\title{
Introduction to the special issue on comfort: A review of 26 papers from the International Comfort Congress 2019
}

\author{
Peter Vink $^{\mathrm{a}, *}$, Susanne Frohriep ${ }^{\mathrm{b}}$, Neil Mansfield ${ }^{\mathrm{c}}$, Alessandro Naddeo $^{\mathrm{d}}$ and Karen Jacobs ${ }^{\mathrm{e}}$ \\ ${ }^{a}$ Faculty of Industrial Design Engineering, Delft University of Technology, Delft, The Netherlands \\ ${ }^{\mathrm{b}}$ Grammer AG, Kümmersbruck, Germany \\ ${ }^{\mathrm{c}}$ Department of Engineering, School of Science and Technology, Nottingham Trent University, UK \\ ${ }^{\mathrm{d}}$ Department of Industrial Engineering, University of Salerno, Fisciano, Italy \\ ${ }^{\mathrm{e}}$ Department of Occupational Therapy, Boston University, Boston, MA, USA
}

\begin{abstract}
Various aspects related to comfort are described in this special issue. Some papers are focused on the environment, like smell, temperature, light, acoustics, space and some on an artefact touching the human, like the floor angle, the seat, a bed and light. However, in this special issue also topics like modelling and behavior get more attention.
\end{abstract}

Keywords: Review, comfort, model, main findings, ICC2019

\section{Introduction}

Comfort is a daily human experience central to the perception of our environment and the continuous processing of sensorial input [1]. When buying a public transportation ticket, a bed, an office chair, or a car, comfort comes into play. After purchase, comfort is also experienced in travelling, wearing clothes, lying in bed, using hand tools, kitchen appliances and computers. Another possibility is that discomfort comes into play as a negative experiencing of a space or whilst using a product. Some discomfort experiences are widely acknowledged: sitting in a cramped position in an airplane or having sore muscles using a hand tool is experienced as discomfort universally [2]. Comfort is often considered as luxury. It

\footnotetext{
*Address for correspondence: Peter Vink, Faculty of Industrial Design Engineering, Delft University of Technology, Landbergstraat 15, 2628CE, Delft, The Netherlands. E-mail: p.vink@ tudelft.nl.
}

is also related to luxury in the attributes named in association with the term [3]. Avoidance of discomfort is often considered as necessity. Furthermore, discomfort is accepted as a common precursor for chronic musculoskeletal complaints and long term loss of well-being (e.g. Hamberg et al. [4]).

A questionnaire administered to 155 students (of mainly Dutch and Chinese nationalities) asked what they associated with the term 'comfort' [2]. Beds and chairs were mentioned most frequently in their responses. Whilst studies regarding the bed and seat were indeed presented at the 2nd International Comfort Congress, and are included in this special issue on comfort, there are many other environments where comfort is a focus for scientific study. Bazley [5] studied 318 scientific papers with "discomfort" in the title in a period of 10 years. These papers mostly concerned studies on physical human body interaction, which is also the main topic of the papers in this special issue. Bazley [5] also mentioned that 
Table 1

Number of authors and co-authors per country in this special issue

\begin{tabular}{lc}
\hline Italy & 24 \\
UK & 17 \\
China & 17 \\
Netherlands & 12 \\
Germany & 12 \\
Canada & 4 \\
France & 4 \\
Belgium & 3 \\
Austria & 3 \\
USA & 1 \\
Brazil & 1 \\
India & 1 \\
Total & 99 \\
\hline
\end{tabular}

much research is still needed in the field of comfort in order to achieve comfortable interiors for all users. Also Vink et al. [6] state that there are many remaining questions about the effects and relationships between environments and human beings. This special issue certainly adds new knowledge in this field, but it is also clear that there is still a need for further studies.

In this editorial, a short overview will be given on the topics covered in the papers, and then selected findings will be discussed.

\section{Overview of the papers}

Out of 75 papers at the International Comfort Congress 2019, 26 were selected for this special issue. Ninety-nine authors and co-authors from 12 countries contributed to this special issue (see Table 1) and 44 peer reviewers gave independent critical comment on the papers before acceptance (two reviewers per paper, see acknowledgement). The topics studied often concern aircraft interiors (see Table 2), in which improvements can boost passenger comfort, and automotive interiors, a field which is rapidly changing as autonomous driving and electric driving are being introduced, and requiring new comfort knowledge. The office, the bed and the train interior is studied as well. Often the input is varied, and the effect on comfort and on another parameter is tested. In most of the papers an experiment-based approach, both in vehicle and in VR/Lab setup, is used for assessing comfort and evaluating the influencing factors; also modeling-based and a hybrid (numerical/experimental) approach is used for determining influences of some factors (layout, geometry, interaction) through Computer-Aided simulation. The study
Table 2

Topics studied in the 26 papers

\begin{tabular}{lcc}
\hline $\begin{array}{l}\text { First author of } \\
\text { the paper }\end{array}$ & $\begin{array}{c}\text { Position in } \\
\text { model }\end{array}$ & $\begin{array}{c}\text { Application } \\
\text { field }\end{array}$ \\
\hline Anjani & Space & Airplane \\
Anjani & Questionnaire & General \\
Backes & Temperature & Automotive \\
Burkhard & Behaviour & Automotive \\
Califano & Seat & Classroom \\
Cappetti & Modelling & Sitting \\
Erol & Seat & Automotive \\
Fiorillo & Seat & Classroom \\
Gentner & Smell & Automotive \\
Han & Light & Office \\
Liu S & Modelling & Airplane \\
Liu Z & Space & Airplane \\
Liu Z & Floor & Standing \\
Mansfield & Seat & Automotive \\
Moertl & Acoustics & Automotive \\
Naddeo & Seat & Automotive \\
Naddeo & Bed & Bed \\
Sharafkhani & Behaviour & Airplane \\
Smith & Seat & Train \\
Tang & Seat & Train \\
Torkashvand & Space & Airplane \\
Torkashvand & Behaviour & Airplane \\
Udomboonyanupap & Bed & Bed \\
Vanacore & Seat & Airplane \\
Wang & Seat & Automotive \\
Yao & Smell & Airplane \\
\hline & &
\end{tabular}

of Anjani et al. in this special issue is not focusing on one application area but instead provides an overview of all comfort and discomfort questionnaires and their recommended usage, which can be an important basis for future research. For a specific product and a specific phase in the design process the most relevant questionnaires are named based on a study with 55 comfort experts.

\section{Introduction to selected findings}

As in the previous special issue on environmental design in this journal [6], different aspects of the environment are studied in the papers in this special issue in a similar approach (see Fig. 1): aspects that are distant from the human body (the environment), more close and even touching the human body (e.g. the seat and the bed) and aspects that concern human behavior (e.g. movement). This last aspect is not studied so much, but it is also an important factor. If, for instance, we follow the comfortable office interior guidelines for temperature, many of us might feel comfortable. However, if we change our behavior, like exercise at the office or putting on our warm sweater, the guidelines are less useful [7]. The papers 


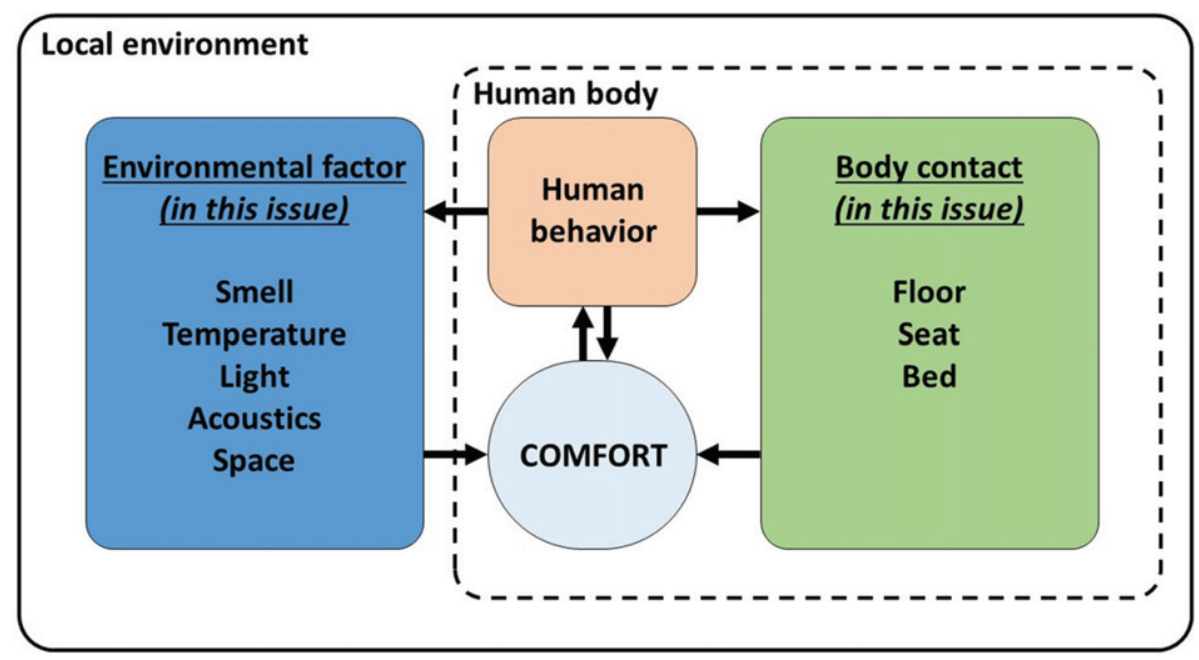

Fig. 1. A model positioning the papers of this special issue: Some are focused on the environment, some on an artefact touching the human body and some on behavior. Other factors and contact types are important but not included in this special issue.

can be positioned in the model of Fig. 1, which will be discussed in the next paragraph.

\subsection{The environment: Smell}

An aspect of the environment that is not often studied is the relationship between scent and comfort. There are two papers in this special issue on smell and comfort. Yao et al. showed that the preferences for scents vary a lot between individuals, which makes it difficult to add one type of scent to an aircraft interior that makes 'everybody' feel more comfortable. Even for the scent 'mandarin', which was appreciated by many passengers, the preferred intensity varied. Gentner et al. indicated that olfactory comfort has a large effect on the overall comfort perception in personal cars, comparable in weight to the effect of thermal comfort.

\subsection{The environment: Temperature}

Backes et al. demonstrated that radiative heating panels are more energy efficient than heating the air of the car (30\% reduction of energy consumption) and the same quality of comfort can be achieved, and time to comfort was even faster with this technology.

\subsection{The environment: Light}

Han et al. indicated that users felt more comfortable with high intensity warm lights using a computer screen. This intensity also reduced the visual and cognitive fatigue. Further relevant findings are that in this study, eye fixation duration had a significant negative correlation with comfort, while blink duration had a significant correlation with discomfort.

\subsection{The environment: Acoustics}

Moertl et al. showed that under higher workload, participants reported higher acoustic discomfort for the same sounds than under lower workload.

\subsection{The environment: Space and floorplan}

The space in an aircraft influences comfort, but maintaining the same comfort, the space can be used in a more economic way. The paper of Anjani et al. on the floorplan in an aircraft shows that some in a group of 88 experts were able to position seats in the same space with the same comfort in such a way that an airline can make more revenue. It shows that investing in time and staff and studying the literature to make floorplans can increase revenue. Also Zhihui Liu et al. demonstrate the benefit of research and show that space influences comfort. The pitch of staggered seats does influence comfort. Staggered seats give a more spacious feeling, but at 28" pitch also staggered seats show an unacceptable low comfort level. Also interesting to see is that the advantage of staggered seats is that the shoulders do not come into contact and there is space on the armrests for every elbow. Sitting close to each other could hinder privacy. In the paper of Torkashvand et al., passengers experienced an aircraft seat in VR where there is a separa- 
tion from the rest of the aircraft and the passengers stated that they would like this because of improved privacy.

\subsection{Close to the body: Floor}

The floor itself can also influence comfort. Zhihui Liu asked participants to stand on various sloped floors to improve comfort. The experienced fatigue was lowest at 5 and 10 degrees. So, it might be beneficial for workers doing standing work to vary the slope on which they stand.

\subsection{Close to the body: Seat characteristics}

The seat characteristics influence comfort as well. The visual impression plays a role. Based on showing car seat images, Erol et al. could conclude that "comfortable" is a descriptor item that significantly differentiated seats. Vanacore found that the overall seating comfort perception is significantly influenced by the thickness of the seat pan, the backrest position (upright or reclined) and being comfortably supported at the lumbar region. Mansfield et al. demonstrated that a well-designed neckrest is beneficial for drivers in the autonomous driving mode. Naddeo et al. added a sacral support to a car seat and in real driving conditions this led to an improvement in comfort perception compared with a standard seat. Fiorillo et al. studied the comfort of a library chair and the lumbar area scored lowest for comfort, mainly because of the lack of support. Smith et al. demonstrated a good correlation between seat dimensions and comfort score for train seats. A step further is shaping the cushion to the human body. Wang et al. showed that a thinner cushion that is well shaped can initially reduce discomfort. Tang et al. showed that a front protruding cushion made the pressure distribution more even, while a flat cushion had the highest comfort score. While this seems contradictory at first, it points to the fact that sitting positions are not static, and the human body needs to be supported in different postures. If the cushion shape can adapt to the respective individual body contours in different sitting positions, the highest comfort will be achievable. Based on the papers in this special issue, a seat should have a seat pan that is flat, have the ability to adapt to the form of the buttocks and should have adequate thickness, should have a sacral and a lumbar support, and a good neck support when driving in autonomous mode, and the seat should be adjustable to the anthropometric dimensions of the user population.

\subsection{Close to the body: Bed characteristics}

It is also important to make beds more adaptive to user anthropometrics. In an experiment, Naddeo and Cappetti changed the middle layer of a mattress to adapt it to the anthropometrics of the user. Their results show that personalized products can be tuned to the anthropometric data of the customer improving the comfort experience during sleep. Smart phoning is also done in bed. Udomboonyanupap et al. changed the trunk angle while smart phoning in a bed and found an optimal range to create comfort for this frequent use case.

\subsection{Close to the body: Hands and visual}

Inputs at the hands and visual system are important for those concerned with effects of ambient light (e.g. Han et al.) and those concerned with operators of vehicles or other systems (e.g. Mansfield et al.).

\subsection{Behavior}

Human behavior certainly influences comfort, and it is influenced by the respective environment. If the possibility to move is restricted, the comfort usually drops. Sharafkhani et al. showed that posture variation is hardly possible in an aircraft seat, and when passengers take a posture with the head rotated more downward, the comfort detriment is faster than for positions with a more upright head position. This posture variation is also important for sleeping. In the study of Torkashvand sleeping/relaxing was the activity with lowest comfort according to passenger perception by flight attendants, which was the same as mentioned by passengers. Flight attendants seem to know quite well what elements aircraft passengers prefer to change to increase comfort. Sometimes behavior is determined by the task. Mansfield et al. highlight with their research in car seats that discomfort is worse for cases where the posture is non-optimal for the task. In studying a combodesk in a classroom, Califano et al. found that the task-related upper limb activity is one of the most influencing factors in the overall comfort perception. Moertl et al. state that cognitive processes impact physiological comfort through focusing attention or masking, whereas emotional comfort is influenced through an emotional appraisal process. Burkhard et al. described that inattentive occupants in a car move their head relatively more, which could mean that there is less anticipation. In this case also the 
task 'not driving' could influence comfort. A finding described before (e.g. Sammonds et al. [7] and Smulders et al. [8]) is that longer sitting reduces comfort. A task that determines prolonged sitting can lower the comfort score. Fiorillo et al. studied the comfort of a library chair and the perceived comfort was similarly dependent on time in that longer sitting reduced comfort.

\subsection{Modelling can be of help in creating comfort}

Sean Liu et al. showed that using biomechanics for force and contact mechanics for pressure distribution a model can fairly well predict parameters relevant for comfort. Cappetti et al. made a model of the interaction between a human and a seat and with this model, the postures that occupants take can be predicted.

\section{Conclusion}

In comfort, the traditional topics like seats are still studied, but in this special issue also topics like behavior get more attention. We wish you much reading pleasure.

\section{Acknowledgments}

The editors would like to thank all authors and reviewers for their contribution. The reviewers were: Albin, T, High Plains Engineering Services; Bazley, C; Boess, S, TU-Delft; Bronkhorst, R, TU-Delft; Brütting, M, DGUV; Burkhard, G, BMW; Buso, A, TU-Delft; Cappetti, N, University of Salerno; Castro, A, Alma Design; Diels, C, IMDC; Erol, T, NTDC; Faulkner, S, NTU; Frohriep, S, Grammer AG; Happee, R, TU-Delft; Huysmans, T, TU-Delft; Kamp, I, Amsterdam University of Applied Sciences; Kim, EY, TU-Delft; Kühne, M, VHP human performance; Le, F, Safran; Li, W, Northwestern
Polytechnical University; Liu, Z, Donghua University; Mansfield, N, NTU; Mellert, V, ITAP; Miguez, S, ErgoSys; Moertl, P, Virtual Vehicle Research Center; Molenbroek, J, TU-Delft; Naddeo, A, University of Salerno; Ozcan, E, TU-Delft; Post, J, KLM; Roelofsen, P, TU-Delft; Sagar, D, TU-Delft; Schliwa, R, Airbus; Sharafkani, M, University of Nottingham; Silvester, S, TU-Delft; Sisman, V, Transilvania University of Brasov; Smulders, M, TU-Delft; Song, Y, TU-Delft; Torkashvand, G, Florida Institute of Technology; Udomboonyanupap, S, TU-Delft; Vanacore, A, University of Naples Federico II; Vink, P., TU Delft; Wang, X, IFSTTAR; Wegner, M, BMW; Yao, $\mathrm{X}$, TU-Delft; Zagorski, WP, Lear Corporation.

\section{References}

[1] Mansfield N, Naddeo A, Frohriep S, Vink P. Integrating and applying models of comfort. Applied Ergonomics. 2020;82:102917.

[2] Vink P, Anjani S, Udomboonyanupap S, Torkashvand G, Albin T, Miguez S, Lie W, Reuter C, Vanacore A. Differences and similarities in comfort and discomfort experience in nine countries in Asia, the Americas and Europe. Accepted for publication in Ergonomics. 2020.

[3] Helander MG, Zhang L. Field studies of comfort and discomfort in sitting. Ergonomics. 1997;40(9):895-915.

[4] Hamberg-van Reenen HH, Beek AJ, Blatter BM, Grinten MP van der, Mechelen W van, Bongers PM. Does musculoskeletal discomfort at work predict future musculoskeletal pain? Ergonomics. 2008;51(5):637-48.

[5] Bazley CM. Beyond Comfort in Built Environments. PhD thesis TU-Delft, Delft. 2015.

[6] Vink P, Bazley C, Jacobs K. Modeling the relationship between the environment and human experiences. Work. 2016;54(4):765-71.

[7] Roelofsen P, Modelling relationships between a comfortable indoor environment, perception and performance change. $\mathrm{PhD}$ thesis TU-Delft, Delft. 2016.

[8] Sammonds GM, Fray M, Mansfield NJ. Effect of long term driving on driver discomfort and its relationship with seat fidgets and movements (SFMs). Applied Ergonomics. 2017;58:119-27.

[9] Smulders M, Berghman K, Koenraads M, Kane JA, Krishna $\mathrm{K}$, Carter TK, Schultheis U. Comfort and pressure distribution in a human contour shaped aircraft seat (developed with 3D scans of the human body). Work. 2016;54(4):925-40. 